\title{
HUBUNGAN ANTARA RAWAN BOSAN DAN KEMUDAHAN TERTIDUR DENGAN MICROSLEEP SAAT MENGEMUDI
}

\author{
Arjun Indru Moorjani ${ }^{1}$ dan Leksmono Suryo Putranto ${ }^{2}$ \\ ${ }^{1}$ Program Studi Sarjana Teknik Sipil, Universitas Tarumanagara, Jl. Letjen S. Parman No.1 Jakarta \\ arjun.325150162@stu.untar.ac.id \\ ${ }^{2}$ Program Studi Sarjana Teknik Sipil, Universitas Tarumanagara, Jl. Letjen S. Parman No.1 Jakarta \\ leksmonop@ft.untar.ac.id
}

\begin{abstract}
One of the most common types of sleepiness experienced by drivers is microsleep. Microsleep causes the driver to lose control of his or her vehicle, resulting in accidents that could be fatal. This study aims to determine the effect of boredom proneness and the driver's level of ease of falling asleep on the frequency of occurrence of microsleep while driving. Boredom proneness and ease of falling asleep were measured using questions adopted from the Boredom proneness Scale and Epworth Sleepiness Scale, respectively, while microsleep was calculated using a questionnaire to determine the frequency of microsleep experienced by the driver. The research data were analyzed using the Structural Equation Modeling (SEM) analysis method to calculate the correlation value between research variables. The results of the analysis show that boredom proneness and ease of falling asleep are significantly and positively correlated with the likelihood of someone experiencing microsleep while driving, where boredom proneness is also positively and significantly correlated with ease of falling asleep. There was no significant difference found in the Boredom proneness Scale scores, Epworth Sleepiness Scale scores, and frequency of experiencing microsleep whilst driving between the genders.
\end{abstract}

Keywords: microsleep; boredom proneness; ease of falling asleep; driving

\begin{abstract}
ABSTRAK
Salah satu jenis kantuk yang paling sering dialami oleh pengemudi dalam berkendara adalah microsleep. Microsleep mengakibatkan pengemudi kehilangan kontrol akan kendaraannya, sehingga berakibat sangat fatal terhadap keselamatan berkendara. Penelitian ini bertujuan untuk mengetahui pengaruh boredom proneness (kecenderungan merasa bosan) dan tingkat kemudahan tertidur pengemudi terhadap frekuensi terjadinya microsleep pada saat berkendara. Boredom proneness dan kemudahan tertidur masing-masing diukur menggunakan pertanyaanpertanyaan yang diadopsi dari Boredom proneness Scale dan Epworth Sleepiness Scale, sedangkan microsleep dihitung menggunakan kuesioner untuk menentukan frekuensi microsleep yang dialami pengemudi. Data penelitian dianalisa menggunakan metode analisis Structural Equation Modeling (SEM) untuk menghitung nilai korelasi antar variabel penelitian. Hasil analisis menunjukkan bahwa boredom proneness dan kemudahan tertidur berkorelasi secara signifikan dan positif terhadap kemungkinan seseorang mengalami microsleep saat mengemudi, dimana boredom proneness juga berkorelasi secara positif dan signifikan terhadap kemudahan tertidur. Tidak ditemukan perbedaan signifikan pada tingkat kecenderungan pengemudi merasa bosan (boredom proneness), mudah tertidur, dan mengalami microsleep di antara jenis kelamin. Mereka yang berusia di bawah 30 tahun ditemukan lebih mudah untuk merasa bosan, sehingga lebih rentan untuk mengalami microsleep pada saat mengemudi.
\end{abstract}

Kata kunci: microsleep; boredom proneness; kemudahan tertidur; mengemudi

\section{PENDAHULUAN}

Menurut penelitian dari lembaga keselamatan lalu lintas AAA Foundation (Amerika Serikat), 1 dari 10 kecelakaan lalu lintas disebabkan karena pengemudi mengalami kantuk. Selain itu, AAA Foundation juga mengemukakan bahwa sekitar 24 persen pengemudi mengaku mengemudi dalam keadaan sangat lelah sehingga mereka kesulitan untuk menjaga mata mereka tetap terbuka setidaknya sekali dalam 30 hari terakhir. Dari semua kecelakaan lalu lintas yang fatal yang terjadi di tahun 2018,2,4 persen disebabkan oleh mengemudi dalam keadaan mengantuk 
Salah satu jenis kantuk yang paling sering dialami oleh pengemudi dalam berkendara adalah microsleep. Microsleep merupakan fenomena episode tertidur / kehilangan kesadaran dalam waktu yang singkat sebelum orang tersebut kembali sadar. Microsleep dapat terjadi kapanpun; pada saat mengerjakan hal yang penting ataupun pada saat seseorang tidak melakukan apa-apa. Namun, bahaya terjadinya microsleep sering diasosiasikan dengan kegiatan mengemudi, dimana pengemudi dapat kehilangan kesadaran, meskipun hanya sepersekian detik, yang mengakibatkan pengemudi kehilangan kontrol akan kendaraannya.

Fatalnya kecelakaan yang dapat ditimbulkan oleh microsleep merupakan suatu masalah yang perlu ditelusuri dan dikaji lebih dalam, khususnya pada faktor-faktor yang berkontribusi terhadap terjadinya microsleep saat mengemudi. Studi ini memiliki fokus untuk melihat lebih dalam bagaimana boredom proneness pada pengemudi mempengaruhi kecenderungan terjadinya microsleep.

\section{Boredom proneness}

Kecenderungan mengalami rasa bosan dapat diukur menggunakan Boredom proneness Scale (BPS; Farmer dan Sunberg, 1986). Boredom proneness Scale bersifat self-report (Elpidorou, 2014) dan merupakan skala lengkap yang mencoba menangkap fenomena kecenderungan untuk mengalami kejenuhan secara komprehensif (Struk et al., 2015). Boredom proneness Scale memiliki nilai reliabilitas konsistensi internal $(\alpha=0,79)$ dan reliabilitas tes-retes $(\mathrm{r}=0,83)$ serta nilai validitas kriteria $(\alpha=0,67)$ (Farmer, 1986).

\section{Epworth Sleepiness Scale}

Epworth Sleepiness Scale (ESS) adalah kuesioner bersifat self-administered yang dapat mengukur tingkat rasa kantuk seseorang pada siang hari secara umum. Responden dapat menilai kemungkinan mereka akan tertidur atau tertidur ketika berada dalam delapan situasi berbeda yang biasa dihadapi dalam kehidupan sehari-hari. ESS terdiri dari 8 pertanyaan yang wajib diisi oleh seluruh responden; dimana masing-masing pertanyaan memiliki skor 0-3 (sesuai dengan derajat keluhan mengantuk). Skor total merupakan penjumlahan skor dari 8 pertanyaan tersebut. (Johns, 1991). Dalam penelitian Johns (1991), total skor ESS secara signifikan membedakan subjek normal dari pasien dalam berbagai kelompok diagnostik termasuk sindrom apnea tidur obstruktif, narkolepsi, dan hipersomnia idiopatik. Skor ESS secara signifikan berkorelasi dengan latensi tidur yang diukur selama tes latensi tidur ganda dan selama polisomnografi semalam. Pada pasien dengan sindrom apnea tidur obstruktif, skor ESS secara signifikan berkorelasi dengan indeks gangguan pernapasan dan minimum $\mathrm{SaO}_{2}$ (saturasi oksigen) yang dicatat dalam semalam. Skor ESS pasien yang hanya mendengkur tidak berbeda dari skor ESS pasien kontrol.

\section{Microsleep dan pengukuran microsleep}

Microsleep adalah episode singkat dari perilaku pola tidur dan penghentian respon terhadap target visual motorik atau episode tidur yang terjadi dalam beberapa detik. Dalam keadaan tertentu microsleep dapat menyebabkan kecelakaan yang fatal seperti saat sedang berkendara, mengoperasikan mesin berat, atau saat dokter melakukan operasi, selain itu microsleep juga dapat meningkatkan resiko kecelakaan lalu lintas hingga sebelas kali lipat, namun tidak banyak masyarakat yang menyadari bahwa kelelahan dan mengantuk adalah faktor utama penyebab microsleep yang dapat menyebabkan kecelakaan. (Ariansyah, 2019).

Dalam penelitian ini, microsleep diukur dengan frekuensi terjadinya microsleep saat mengemudi pada subjek penelitian. Subjek penelitian diberikan empat pilihan untuk mengukur frekuensi microsleep yang mereka alami saat mengemudi, yaitu tidak pernah, 1-3 kali, 3-5 kali, dan lebih dari 5 kali pada situasi tertentu. Situasi yang diukur pada penelitian ini adalah situasi-situasi dimana microsleep saat mengemudi rentan terjadi.

\section{METODE PENELITIAN}

Alur penelitian diperlukan untuk memastikan penelitian berjalan dengan baik dengan harapan dapat menjadi pedoman agar penelitian dapat berjalan dengan efisien dan tepat waktu. Data pada penelitian ini dikumpulkan menggunakan kuesioner via google forms kepada responden yang memenuhi kriteria tinggal dan menetap di Indonesia dan pengemudi yang memiliki Surat Izin Mengemudi (SIM A). Analisis data pada penelitian ini bertujuan untuk melihat bagaimana pengaruh boredom proneness terhadap terjadinya microsleep saat mengemudi. Kemudian, berdasarkan hasil analisis data dibuat sebuah kesimpulan dan saran dengan harapan hal ini dapat berguna bagi penelitian selanjutnya dan masyarakat umum. Alur tahapan penelitian ini dapat dilihat pada gambar 1 . 


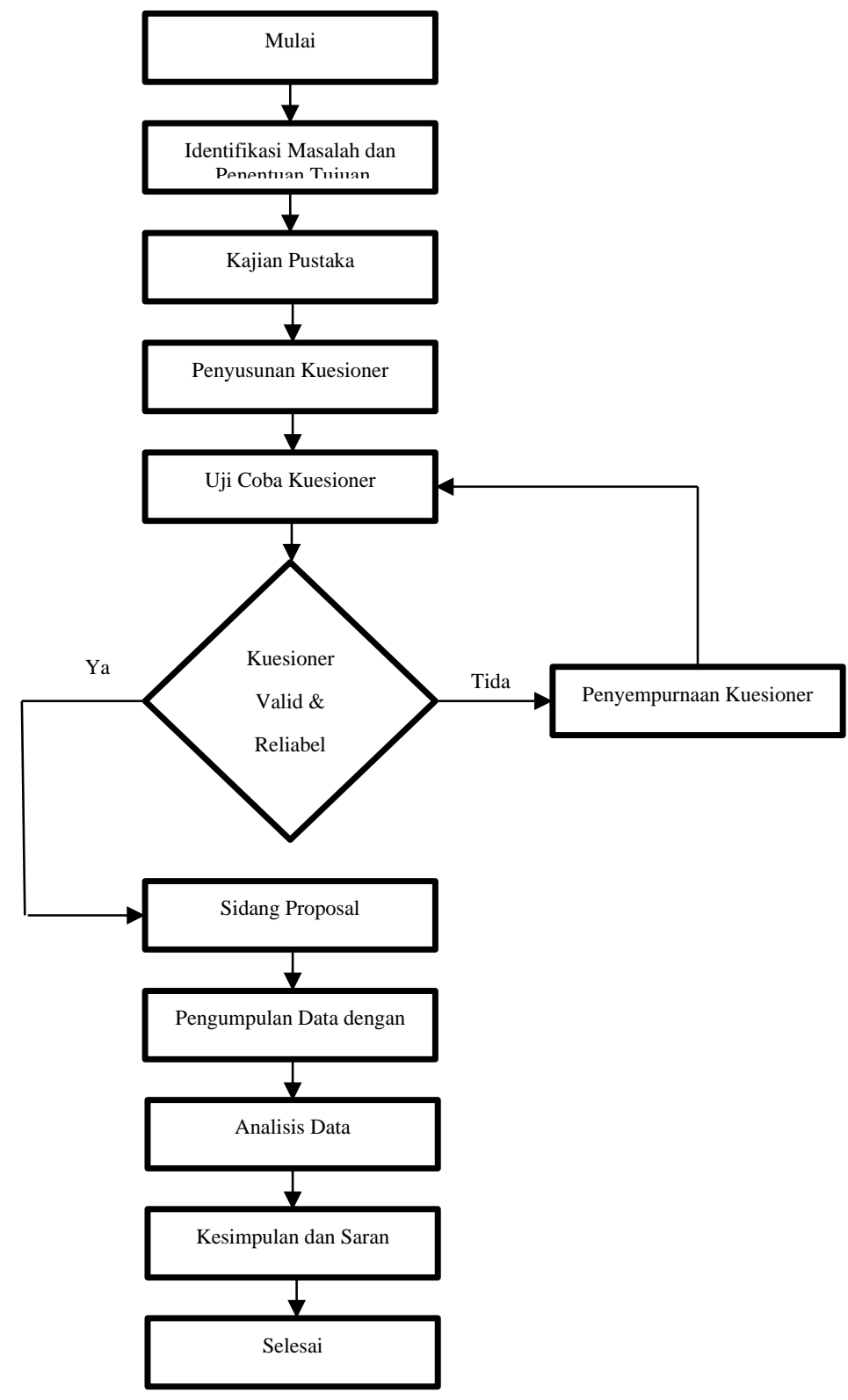

Gambar 1. Diagram alur penelitian

\section{Kuesioner}

Dalam penelitian ini, metode skala Likert digunnakan berbeda untuk dua alat ukur, yaitu pada alat ukur Boredom proneness Scale (BPS) dan Epworth Sleepiness Scale (ESS). Pada alat ukur boredom proneness responden diminta untuk memilih pernyataan yang paling sesuai dengan dirinya. Skala Likert terdiri dari empat pernyataan sikap yaitu Sangat Tidak Setuju (STS), Tidak Setuju (TS), Setuju (S), Sangat Setuju (SS).

Pada alat ukur Epworth Sleepiness Scale responden diminta untuk memilih pernyataan yang paling sesuai dengan dirinya. Skala Likert terdiri dari empat pernyataan sikap yaitu Tidak akan pernah tertidur, Peluang rendah untuk tertidur, Peluang sedang untuk tertidur, Peluang tinggi untuk tertidur.

Selanjutnya, pengukuran kuesioner microsleep saat mengemudi, menggunakan skala frekuensi untuk mengukur seberapa sering terjadinya microsleep pada responden saat mengemudi. Skala frekuensi terdiri dari empat pilihan, yaitu Tidak Pernah, 1-2 kali, 3-5 kali, dan >5 kali. Hasil uji validitas dan reliabilitas kuesioner pada bagian boredom proneness bisa di lihat pada tabel 1 dan 2 . 
Tabel 1. Hasil uji validitas dan reliabilitas - Boredom proneness - Extremely Bored

\begin{tabular}{lll}
\hline \multirow{2}{*}{ No. } & \multicolumn{1}{c}{ Boredom proneness (Extremely Bored) } & Nilai Cronbach's Alpha $=\mathbf{0 , 8 3 2}$ \\
\cline { 2 - 3 } & \multicolumn{1}{c}{ Pertanyaan } & Valid \\
\hline BP1 & Ketika bekerja saya sering merasa diri saya mengkhawatirkan hal- hal lain & Valid \\
\hline BP2 & Dibutuhkan lebih banyak stimulasi (dorongan) untuk membuat saya maju daripada orang lain & Valid \\
\hline BP3 & Saya sering menemukan diri saya mengalami “jalan buntu” dan tidak tahu apa yang harus dilakukan & Valid \\
\hline BP4 & Saya sering terjebak pada situasi dimana saya melakukan hal-hal yang tidak bermakna & Valid \\
\hline BP5 & Melihat video keluarga atau foto perjalanan seseorang membuat saya sangat bosan & Valid \\
\hline BP6 & Hal-hal yang saya lakukan bersifat berulang-ulang dan monoton & Valid \\
\hline BP7 & Waktu sepertinya berlalu sangat lambat & Valid \\
\hline BP8 & Saya jarang bersemangat jika melakukan pekerjaan saya & Valid \\
\hline BP9 & Sebagian besar waktu saya gunnakan tanpa melakukan apapun & Tidak \\
\hline BP10 & Saya sulit mencari waktu luang & Valid \\
\hline BP11 & Dalam situasi di mana saya harus menunggu, seperti antrian, saya menjadi sangat gelisah & Valid \\
\hline BP12 & Akan sangat sulit bagi saya untuk menemukan pekerjaan yang cukup menarik & Valid \\
\hline BP13 & Saya merasa bahwa saya bekerja di bawah kemampuan saya hampir sepanjang waktu & Valid \\
\hline BP14 & Kecuali jika saya melakukan sesuatu yang menarik, bahkan berbahaya, saya merasa sangat bosan. & Valid \\
\hline BP15 & Butuh banyak perubahan dan variasi untuk membuat saya benar-benar bahagia & Valid \\
\hline BP16 & Acara telivisi atau film di cinema, terlihat begitu-begitu saja, sangat kuno. & Valid \\
\hline BP17 & Ketika saya masih muda, saya sering berada dalam situasi yang monoton dan melelahkan & Valid \\
\hline BP18 & Di antara teman-teman saya, saya yang terus melakukan sesuatu paling lambat & Valid \\
\hline
\end{tabular}

Tabel 2. Hasil uji validitas dan reliabilitas - Boredom proneness - Extremely Interested

\begin{tabular}{llc}
\hline \multirow{2}{*}{ No. } & \multicolumn{1}{c}{ Boredom proneness (Extremely Interested) } & \multirow{2}{*}{ Kriteria } \\
\cline { 2 - 3 } & \multicolumn{1}{c}{ Pertanyaan } & Vronbach's Alpha $\mathbf{0 . 7 6 4}$ \\
\hline BP 19 & Mudah bagi saya untuk berkonsentrasi pada aktivitas saya & Valid \\
\hline BP 20 & Sepanjang waktu saya memproyeksikan dalam pikiran saya tentang hal-hal yang harus dilakukan & Valid \\
\hline BP 21 & Saya merasa mudah untuk menghibur diri sendiri & Valid \\
\hline BP 22 & Saya mendapat banyak pujian dari apa yang saya lakukan & Valid \\
\hline BP 23 & Didalam kondisi apapun saya terbiasa mencari sesuatu agar minat saya terjaga & Valid \\
\hline BP 24 & Saya suka menunggu dengan sabar & Valid \\
\hline BP 25 & Saya sering terbangun dengan ide baru & Valid \\
\hline BP 26 & Saya ingin melakukan hal-hal yang lebih menantang dalam hidup & Valid \\
\hline BP 27 & Banyak orang akan mengatakan bahwa saya orang yang kreatif atau imajinatif & Valid \\
\hline BP 28 & Saya memiliki banyak minat, saya tidak punyawaktu untuk melakukan semuanya & Valid \\
\hline
\end{tabular}


Hasil uji validitas dan reliabilitas kuesioner pada bagian epworth sleepiness scale dan microsleep bisa di lihat pada tabel 3 dan 4.

Tabel 3. Hasil uji validitas dan reliabilitas - Epworth Sleepiness Scale

\begin{tabular}{|c|c|c|}
\hline \multirow{3}{*}{ No. } & Epworth Sleepiness Scale & \multirow{3}{*}{ Kriteria } \\
\hline & Nilai Cronbach's Alpha $=0,608$ & \\
\hline & Pertanyaan & \\
\hline ESS 1 & Baca sambil duduk & Valid \\
\hline ESS 2 & Menonton TV & Valid \\
\hline ESS 3 & Duduk, tidak aktif di tempat umum (misalnya cinema/bioskop atau di saat sedang rapat.) & Valid \\
\hline ESS 4 & Sebagai penumpang di dalam mobil selama satu jam tanpa istirahat & Valid \\
\hline ESS 5 & Berbaring untuk beristirahat di sore hari jika keadaan memungkinkan & Valid \\
\hline ESS 6 & Duduk dan berbicara dengan seseorang & Valid \\
\hline ESS 7 & Duduk dengan tenang setelah makan siang tanpa mengkonsumsi alkohol & Valid \\
\hline ESS 8 & Di dalam kendaraan yang terjebak macet. & Valid \\
\hline
\end{tabular}

Tabel 4. Hasil uji validitas dan reliabilitas - frekuensi microsleep saat mengemudi

\begin{tabular}{clc}
\hline \multirow{2}{*}{ No. } & \multicolumn{1}{c}{ Microsleep } & \multirow{2}{*}{ Kriteria } \\
\cline { 2 - 3 } & \multicolumn{1}{c}{ Pertanyaan } & \multicolumn{1}{c}{ Cronbach's Alpha $\mathbf{0 , 8 5 1}$} \\
\hline MS 1 & Saya pernah mengalami microsleep saat mengemudi di kondisi kemacetan. & Valid \\
\hline MS 2 & $\begin{array}{l}\text { Saya pernah mengalami microsleep di saat mengemudi di jalan lurus dan panjang tanpa } \\
\text { hambatan (seperti jalan tol dan jalan antar kota) }\end{array}$ & Valid \\
\hline MS 3 & Saya pernah mengalami microsleep di saat mengemudi pagi pagi sekali/ di pagi hari. & Valid \\
\hline MS 4 & Saya pernah mengalami microsleep di saat mengemudi larut malam & Valid \\
\hline \multirow{2}{*}{ MS 5 } & $\begin{array}{l}\text { Saya pernah mengalami microsleep di saat mengemudi untuk lebih dari satu jam tanpa } \\
\text { istirahat/stop over. }\end{array}$ & Valid \\
\hline
\end{tabular}

\section{HASIL DAN PEMBAHASAN}

Analisis perbandingan hasil Boredom proneness (BP), Epworth Sleepiness Scale (ESS), dan Microsleep pada kelompok responden dilakukan untuk memahami lebih dalam mengenai kelompok masyarakat manakah yang menunjukkan kecenderungan merasa bosan lebih tinggi, memiliki hasil skor ESS yang mengindikasikan kemungkinan adanya gangguan tidur, dan frekuensi mengalami microsleep.

Perbandingan dilakukan dengan mengelompokkan responden berdasarkan jenis kelamin (Laki-laki dan Perempuan), pekerjaan (Mahasiswa/pelajar dan Lainnya), dan usia. Dalam mengelompokkan responden berdasarkan kelompok usia, dilakukan dua perbandingan, dimana perbandingan pertama membandingkan kelompok usia di bawah 25 tahun $(<25)$ dan di atas atau sama dengan 25 tahun $(\geq 25)$, sedangkan perbandingan kedua membandingkan kelompok usia di bawah 30 tahun $(<30)$ dan di atas atau sama dengan 30 tahun $(\geq 30)$. Dua perbandingan berbeda dilakukan untuk menganalisis apakah terdapat kecenderungan terjadinya BP, ESS, dan Microsleep lebih tinggi pada kelompok masyarakat dengan usia lebih tua. Hasil rata-rata berdasarkan kuesioner dirangkum pada tabel 5 sampai tabel 7.

Tabel 5. Hasil rata rata kuesioner berdasarkan jenis kelamin

\begin{tabular}{cccccc}
\hline & & N & BP & ESS & MS \\
\hline \multirow{2}{*}{ Jenis } & Laki Laki & 81 & 63,48 & 11,68 & 9,28 \\
\cline { 2 - 6 } Kelamin & Perempuan & 71 & 63,06 & 10,82 & 7,55 \\
\hline
\end{tabular}


Terlihat pada tabel 5 , terdapat perbedaan yang sangat kecil antara hasil skor rata-rata BP $(\Delta=0,42)$ dan ESS $(\Delta$ $=0,86$ ) pada Laki-laki dan Perempuan. Dapat disimpulkan bahwa tidak ada perbedaan signifikan dalam kecenderungan merasa bosan dan lebih mudah untuk tertidur yang dialami oleh kedua jenis kelamin. Namun, terdapat perbedaan yang cukup signifikan pada hasil skor rata-rata microsleep antara Laki-laki dan Perempuan $(\Delta$ $=1,73$ ), mengindikasikan bahwa laki-laki berisiko lebih tinggi mengalami microsleep saat mengemudi meskipun memiliki skor BP dan ESS yang tidak begitu berbeda dengan perempuan.

Tabel 6 Hasil rata rata kuesioner berdasarkan pekerjaan

\begin{tabular}{cccccc}
\hline & & N & BP & ESS & MS \\
\hline $\begin{array}{c}\text { Umur } \\
\text { Pembatasan } \\
\text { 30 Tahun }\end{array}$ & Umur $<30$ & 141 & 63,79 & 11,21 & 8,5 \\
\cline { 2 - 6 } & Umur $\geq 30$ & 11 & 56,73 & 12,18 & 8,18 \\
\hline
\end{tabular}

Terlihat pada tabel 6 , terdapat perbedaan yang jelas dan signifikan $(\Delta=4,06)$ antara nilai BP Mahasiswa/Pelajar dengan mereka yang bekerja, menunjukkan bahwa Mahasiswa/Pelajar lebih cenderung mudah bosan. Apabila hipotesis penelitian ini terbukti, bahwa BP dan ESS berpengaruh pada terjadinya Microsleep, terlepas dari skor ratarata MS yang lebih rendah untuk Mahasiswa/Pelajar, dapat disimpulkan bahwa Mahasiswa/Pelajar memiliki risiko lebih tinggi mengalami microsleep saat mengemudi.

Tabel 7 Hasil rata rata kuesioner berdasarkan umur

\begin{tabular}{cccccc}
\hline & & N & BP & ESS & MS \\
\hline \multirow{2}{*}{ Pekerjaan } & Mahasiswa/Pelajar & 51 & 65,98 & 11,08 & 8,35 \\
\cline { 2 - 6 } & Lainya & 101 & 61,92 & 11,38 & 8,53 \\
\hline
\end{tabular}

Meskipun perbedaan skor MS pada perbandingan kelompok usia tabel 7 sangat kecil, terutama jika dibandingkan dengan perbedaan skor MS antar jenis kelamin, dapat dilihat bahwa skor BP dan ESS sangat bervariasi antara kedua kelompok usia tersebut. Rata-rata skor BP untuk responden yang berusia di bawah 30 tahun lebih tinggi $(\Delta=7,06)$ dibandingkan dengan responden yang berusia 30 tahun ke atas. Dapat disimpulkan bahwa responden yang berusia di atas 30 tahun cenderung tidak mudah bosan. Selain itu, skor ESS pada kelompok berusia di atas 30 tahun lebih tinggi $(\Delta=0,97)$ dibandingkan mereka yang berusia di bawah 30 tahun. Dari semua perbandingan antar kelompok responden, perbandingan ini memiliki perbedaan skor ESS terbesar di antara kelompok yang dibandingkan. Ini menunjukkan bahwa seiring bertambahnya usia, semakin tinggi kemungkinan terjadinya gangguan tidur.

\section{Structural Equation Modeling (SEM)}

Pada metode Structural Equation Modeling (SEM), akan dibuat sebuah model persamaan. Model tersebut akan dianalisa dengan data keseluruhan dan dikelompokan. Model SEM final yang terdapat setelah CFA (confirmatory factor analysis) dapat terlihat pada gambar 2, dan hasil goodness of fit dari model 6 SEM terlihat pada tabel 8. 


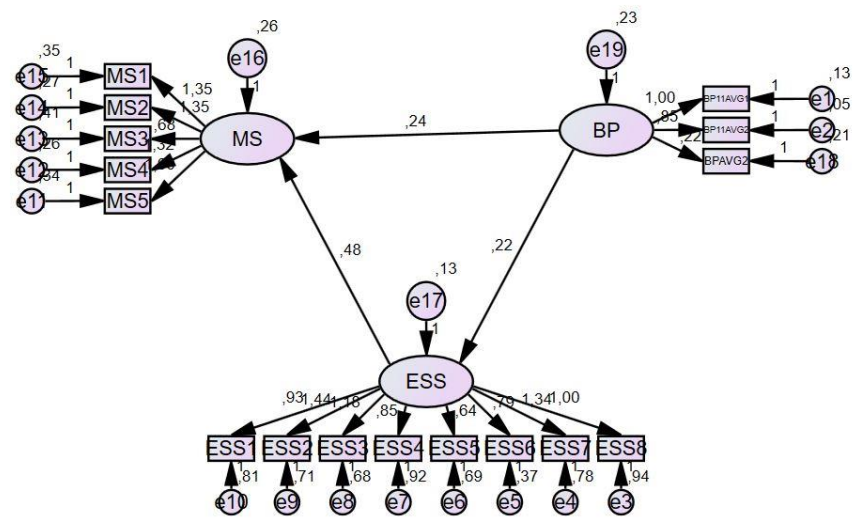

Gambar 2. Model 6 SEM

Tabel 8. Hasil uji kecocokan Model 6 SEM

\begin{tabular}{cccc}
\hline GOODNESS OF FIT & CUT - OFF VALUE & HASIL UJI & KETERANGAN \\
\hline CMIN/DF & $\leq 2,00$ & 1,94 & Good Fit \\
GFI & $\geq 0,90$ & 0,871 & Marginal Fit \\
AGFI & $\geq 0,90$ & 0,826 & Marginal Fit \\
RMSEA & $\leq 0,08$ & 0,079 & Good Fit \\
TLI & $\geq 0,90$ & 0,8 & Marginal Fit \\
CFI & $\geq 0,90$ & 0,832 & Marginal Fit \\
\hline
\end{tabular}

Tabel 8 membuktikan bahwa Model 6 memiliki model fit yang baik, dimana semua indikator goodness of fit masuk dalam kategori good fit atau marginal fit. Ini juga satu-satunya model yang memberikan nilai hasil untuk AGFI dan GFI. Hasil estimate atau hasil pengaruh total indicator terhadap variable bisa dilihat pada tabel 9.

Tabel 9. Hasil pengaruh total indikator terhadap variabel model SEM

\begin{tabular}{cccc}
\hline Indikator 2 & $<---$ & Indikator $\mathbf{1}$ & Estimate \\
\hline ESS & $<---$ & BP & 0,22 \\
\hline MS & $<---$ & BP & 0,346 \\
\hline MS & $<---$ & ESS & 0,485 \\
\hline
\end{tabular}

Terlihat pada tabel 9, bahwa nilai korelasi total BP terhadap MS $(0,346)$ menandakan bahwa ketika nilai BP meningkat sebesar 1 satuan maka nilai MS meningkat sebesar 0,346 satuan. Nilai korelasi estimasi BP terhadap ESS $(0,22)$, hal ini menandakan bahwa ketika nilai BP meningkat sebesar 1 satuan maka nilai ESS meningkat sebesar 0,22 satuan. Estimasi nilai korelasi ESS terhadap MS (0,485), hal ini menandakan bahwa ketika nilai ESS bertambah 1 satuan maka nilai MS bertambah sebesar 0,485 satuan.

\section{KESIMPULAN DAN SARAN}

\section{Kesimpulan}

Berdasarkan penelitian yang dilakukan dapat disimpulkan bahwa:

1. Boredom proneness berkorelasi secara signifikan dan positif terhadap kemungkinan mengalami microsleep saat mengemudi $(\beta=0,346)$.

2. Boredom proneness berkorelasi secara signifikan dan positif terhadap skor Epworth Sleepiness Scale (ESS) individu $(\beta=0,22)$. ESS membantu menentukan seberapa rentan seseorang untuk tidur dalam skenario tertentu dan mengidentifikasi individu yang menderita gangguan tidur tertentu seperti Obstructive Sleep Apnea Syndryome (OSAS).

3. Epworth Sleepiness Scale (ESS) berkorelasi secara signifikan dan positif terhadap kemungkinan seseorang mengalami microsleep saat mengemudi $(\beta=0,485)$. 
4. Seperti asumsi di awal penelitan, tidak ada perbedaan yang signifikan untuk nilai rata-rata Boredom proneness dan Epworth Sleepiness Scale, diantara jenis kelamin.

5. Perbedaan boredom proneness antara responden yang berusia di bawah 30 tahun dan mereka yang berusia di atas 30 adalah perbedaan terbesar dalam skor rata-rata $(7,06)$ yang tercatat dibandingkan dengan semua kelompok dalam analisis. Dapat disimpulkan bahwa mereka yang berusia di bawah 30 tahun secara signifikan lebih rentan terhadap kebosanan dibandingkan dengan mereka yang berusia di atas 30 tahun.

6. Terdapat 3 skenario utama yang menurut responden paling sering mengalami microsleep, yaitu; dalam kondisi kemacetan, di jalan lurus dan panjang tanpa hambatan (seperti jalan tol dan jalan antar kota), dan di saat larut malam.

\section{Saran}

Berdasarkan hasil penilitian, disarankan adanya sosialisasi kepada masyarakat untuk meningkatkan kewaspadaan dan pemahaman faktor-faktor apa saja yang dapat mempengaruhi keamanan mereka saat berkendara, diantaranya boredom proneness dan kemudahan untuk tertidur. Dengan adanya pemahaman yang lebih mendalam, seperti siapa saja kelompok masyarakat yang lebih cenderung memiliki tingkat boredom proneness dan kemudahan tertidur, masyarakat dapat mengambil langkah-langkah pencegahan untuk meminimalisir kemungkinan terjadinya microsleep pada saat berkendara, sehingga membentuk perilaku berkendara yang lebih aman. Selain dari sisi masyarakat, beberapa perbaikan dalam fasilitas yang ada pada jalan dapat membantu meminimalisir terjadinya microsleep khususnya pada 3 skenario utama yang dihadapi oleh pengemudi.

Selain itu, untuk penelitian selanjutnya diharapkan melakukan penyebaran kuesioner secara langsung kepada responden untuk memastikan bahwa responden memahami pertanyaan yang ada, sehingga kualitas data yang didapatkan lebih baik. Menambahkan jumlah responden, setidaknya 30 (untuk memenuhi minimum sample size) pada setiap kelompok umur untuk memastikan representasi data yang lebih valid, sehingga perbandingan hasil peneilitian antar kelompok umur dapat lebih baik

\section{DAFTAR PUSTAKA}

Ariansyah, A., Warta, H., \& Irwan, B. (2019) Perancangan Kampanye Sosial Pencegahan dan Antisipasi Microsleep. Thesis, Desain Komunikasi Visual, Universitas Pasundan.

Elpidorou, A. (2014). The Bright Side of Boredom. Frontiers in Psychology: Switzerland

Farmer, R., \& Sundberg, N. (1986). Boredom proneness-The Development and Correlates of a New Scale. Journal of Personality Assessment, 50(1), Hal. 4-17.

Johns, M. (1991). A New Method for Measuring Daytime Sleepiness: The Epworth Sleepiness Scale. Sleep, 14(6), Hal. 540-545.

Owens, J., Dingus, T., Guo, F., Fang, Y., Perez, M., McClafferty, J. \& Tefft, B. (2018). Prevalence of Drowsy Driving Crashes: Estimates from a Large-Scale Naturalistic Driving Study (Research Brief). Washington, D.C.: AAA Foundation for Traffic Safety.

Struk, A. A., Carriere, J. S.A., Cheyne, J. A., dan Danckert, J. (2017). A Short Boredom proneness Scale: Development and Psychometric Properties. Assessment. 24 (3): Hal. 346-359 